\title{
Comparison of Various Glucocorticoid Replacement Regimens Used in Chronic Adrenal Insufficiency: A Systematic Review
}

\author{
Nduku Kiko ${ }^{\text {a }}$ Atul Kalhan ${ }^{\text {b, c }}$ \\ a Department of Medicine, Kenyatta National Hospital, Nairobi, Kenya; ${ }^{b}$ Royal Glamorgan Hospital, Llantrisant, UK; \\ 'University Hospital of Wales, Cardiff, UK
}

\section{Keywords}

Adrenal · Insufficiency · Glucocorticoid · Outcomes

\begin{abstract}
Objective: Patients with adrenal insufficiency require lifelong glucocorticoid replacement therapy. Hydrocortisone (15-30 mg/day) and prednisolone (3-7.5 mg/day) are the preferred agents used although there is a lack of consensus among endocrinologists regarding the impact of different steroid regimens on quality of life, bone metabolism, cardiometabolic outcomes, adrenal crisis and infections. We carried out a retrospective systematic review of the literature to compare the efficacy and side effects of various glucocorticoid replacement regimens in patients with chronic adrenal insufficiency. Methods: We searched PubMed, Cochrane Reviews and Google Scholar databases up to March 14, 2019, for studies evaluating various clinical outcomes with glucocorticoid replacement therapy. The abstracts and full studies were appraised and data extracted from the eligible studies. The quality of evidence was evaluated and risk of bias carried out. Results: A total of 47 studies including 9 randomised controlled trials (RCTs) and 38 observational studies were evaluated in this systematic review. Prednisolone therapy was observed to be safe as well as efficacious as hydrocorti-
\end{abstract}

karger@karger.com www.karger.com/dde

Karger $\frac{1}{6}$

GOPEN ACCESS
(C) 2020 The Author(s)

Published by S. Karger AG, Basel

This article is licensed under the Creative Commons AttributionNonCommercial-NoDerivatives 4.0 International License (CC BYNC-ND) (http://www.karger.com/Services/OpenAccessLicense) Usage and distribution for commercial purposes as well as any distribution of modified material requires written permission. sone although a higher dose was associated with an increased risk of cardiovascular (CV) disease. A lower hydrocortisone dose (15-20 mg/day) was associated with a reduction of blood pressure and improved clinical outcomes although this observation was based on a solitary RCT. Modified release hydrocortisone was observed to reduce the risk of CV disease based upon results from 2 of the RCTs. However, there was no conclusive evidence of benefit of modified release hydrocortisone and continuous subcutaneous hydrocortisone infusion in improving subjective health status. Conclusion: Prednisolone therapy remains a safe and efficacious alternative to hydrocortisone although there are concerns of dyslipidaemia and CV disease with higher doses. There is limited level I evidence suggestive of a positive effect of modified release hydrocortisone on CV and metabolic outcomes, particularly weight reduction.

(c) 2020 The Author(s)

Published by S. Karger AG, Basel

\section{Introduction}

Adrenal insufficiency refers to inadequate production of glucocorticoids/mineralocorticoids by the adrenal cortex [1-3]. It is broadly divided into primary or secondary adrenal insufficiency based on the predominant organ in- 
volved in pathogenesis. An adrenocortical pathology leads to development of primary adrenal insufficiency in contrast to pituitary/hypothalamic lesions, which results in secondary adrenal insufficiency $[2,4]$.

In clinical practice, active glucocorticoids such as hydrocortisone or prednisolone are preferred therapeutic agents in view of a relatively predictable pharmacokinetics compared to their precursors (cortisone acetate and prednisone) $[1,5]$. Hydrocortisone is commonly used as glucocorticoid replacement, in 3 quarters of patients with adrenal insufficiency, followed by prednisone/prednisolone and cortisol acetate in 11 and $6 \%$ of the patients with adrenal insufficiency, respectively [6]. In recent data compiled from clinics in the UK, $72 \%$ of patients are on hydrocortisone, $26 \%$ on prednisolone and $2 \%$ modified release hydrocortisone [7].

The choice of agent for steroid replacement to use in adrenal insufficiency is paramount as this impacts the health outcomes, including cardiometabolic consequences which are recognised adverse effects of the treatment [2]. Postulated mechanisms for increased cardiometabolic risk in adrenal insufficiency include alteration in physiological cortisol circadian curve and glucocorticoid overreplacement [8]. Selection of glucocorticoid replacement which simulates circadian cortisol rhythm is postulated to be advantageous for metabolic profile in patients with adrenal insufficiency [9]. In contrast, dexamethasone use in adrenal insufficiency is discouraged owing to cushingoid side effects due to improper dose titration [1]. Increase in body weight is a recognised adverse effect associated with most glucocorticoid replacement regimens especially at higher replacement doses. The increase in weight correlates with cardiovascular $(\mathrm{CV})$ risk factors such as worsening of glycaemic control [10]. Quinkler et al. [11] found a statistically significant reduction in both body mass index and glycosylated haemoglobin $\left(\mathrm{HbA}_{1 \mathrm{c}}\right)$ with modified release hydrocortisone compared to the conventional hydrocortisone treatment.

Quality of life is impaired in patients with adrenal insufficiency [12]. In evaluating the quality of life in patients with adrenal insufficiency, recognised confounders include patients' perception of their health, mood changes as well as cognitive changes that may occur in adrenal insufficiency [13]. Maintenance of the physiological cortical circadian levels has an association with improved quality of life in the treatment of patients with Addison's disease [14].

Glucocorticoid replacement in adrenal insufficiency affects bone health with increased risk of osteoporosis

Glucocorticoid Replacement Regimens in

Adrenal Insufficiency and fractures, especially among patients on higher doses of glucocorticoids exceeding $30 \mathrm{mg}$ of hydrocortisone or its equivalent [15]. The dose-dependent effect of glucocorticoids on bone health was also demonstrated by Schulz et al. [16], who reported that lowering the dose of hydrocortisone resulted in an increase in bone mineral density (BMD) and did not predispose to a higher risk of occurrence of adrenal crisis. There has been variation in bone composition among the patients with adrenal insufficiency treated with various glucocorticoid replacement options with lower scores noted in patients treated with prednisolone $[17,18]$. On the other hand, the use of modified release hydrocortisone has been shown to result in improved BMD values [19] although the overall evidence remains conflicting and contentious. A recent study following up patients with primary adrenal insufficiency over 5.5 years showed lower BMD values with prednisolone than hydrocortisone, and no improvement in the values was seen after a change to modified release hydrocortisone [20].

In a systematic review evaluating the glucocorticoid treatment options in adrenal insufficiency, Al Nofal et al. [21] assessed the evidence for differences in various health outcomes in studies published through July 2016 . The review included the quality of life of patients, bone health, mortality and acute events, such as adrenal crises. One of the major limitations observed by the reviewers was the lack of high-quality evidence, particularly related to use of relatively newer steroid preparations such as modified release hydrocortisone. Since 2016, there have been multiple further studies which have been carried out to compare conventional hydrocortisone replacement regimens versus prednisolone or modified release hydrocortisone preparations. Our systematic review was aimed to evaluate the efficacy and impact of various glucocorticoid replacement regimens used in patients with adrenal insufficiency. We used objective benchmarks, such as BMD, cardiometabolic outcomes (including blood pressure, blood glucose, lipid profile, body weight, body mass index, waist circumference) apart from rate of infections and adrenal crises with different glucocorticoid replacement doses and regimens.

\section{Objectives}

To evaluate and compare the efficacy and safety of various glucocorticoid replacement regimens in patients with adrenal insufficiency (prednisolone, hydrocortisone or modified release hydrocortisone).

To determine the optimum dose for glucocorticoid replacement in patients with adrenal insufficiency.

Dubai Diabetes Endocrinol J 2020;26:50-68 DOI: $10.1159 / 000508321$ 
Fig. 1. PRISMA diagram summarising the search process. PAI, primary adrenal insufficiency; SAI, secondary adrenal insufficiency.

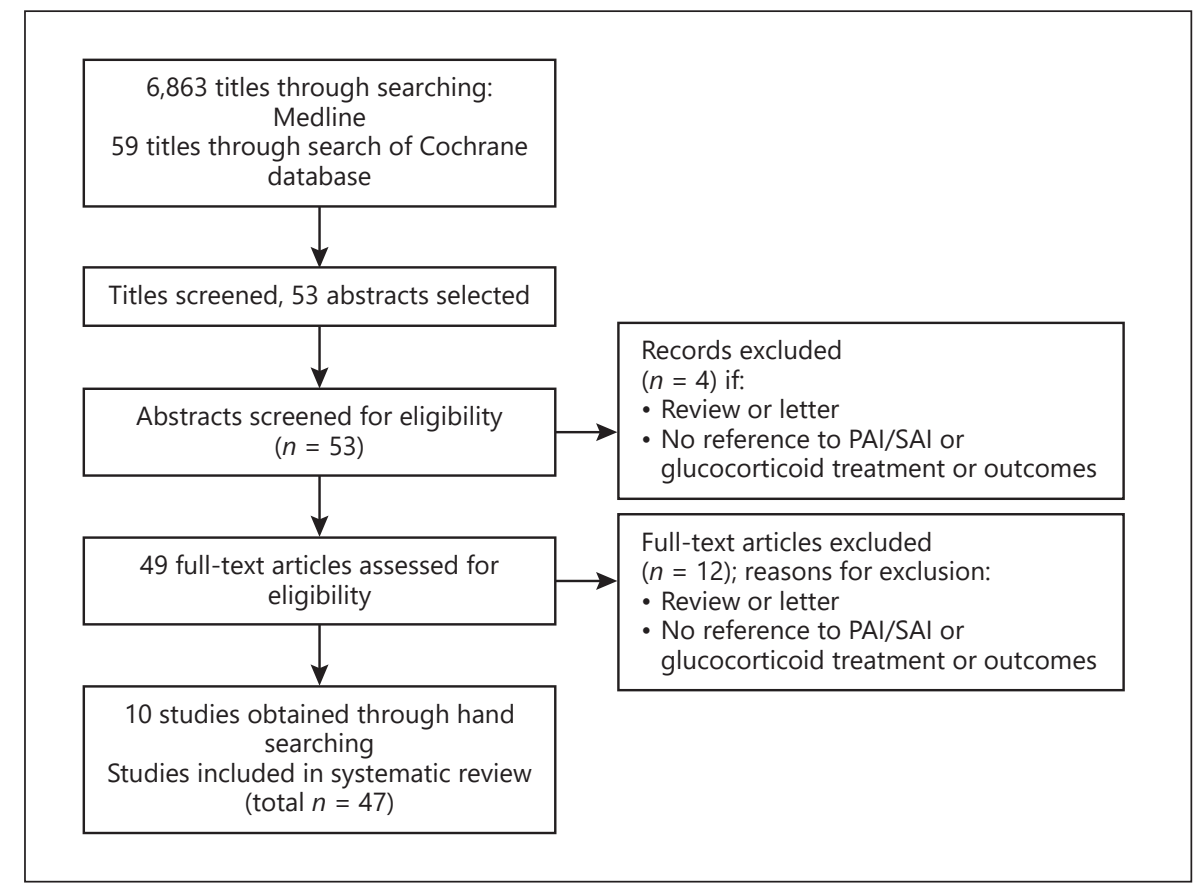

\section{Materials and Methods}

We followed the Preferred Reporting Items for Systematic Reviews and Meta-Analyses (PRISMA) statement which provided a structured overview of the methods recommended to conduct and document the proceedings for the systematic review [22].

\section{Eligibility Criteria}

The following were the inclusion criteria for the studies which were evaluated in this systematic review:

- Studies carried out in an adult population with primary or secondary adrenal insufficiency (patients aged $>18$ years)

- Use of a well-documented steroid replacement regimen (primarily hydrocortisone, prednisolone, dexamethasone) with evaluation of outcomes which included rates of adrenal crises, infections, patient satisfaction, metabolic and CV disease complications (glycaemic control, serum lipids, elevated blood pressure and body weight)

In view of only a limited number of prospective double-blinded randomised control trials (RCTs) which have been carried out in patients with adrenal insufficiency comparing different steroid regimens, observational studies were also included in this systematic review.

Exclusion criteria:

- Case reports

- Studies which were not available in the English language

- All non-original studies.

\section{Data Source and Selection of Studies}

The related studies meeting the inclusion criteria were identified through a search of Medline (1948-2019) using the search terms as follows: "adrenal insufficiency," "Addison disease," "adrenal hypofunction," hypoadrenalism*, hydrocortison*, predniso- lone, dexamethasone, "modified release hydrocortisone," "subcutaneous hydrocortisone," "quality of life," "bone density," fracture*, "adrenal crisis," infection*, weight*, $\mathrm{HbA}_{1 \mathrm{c}}$, "body mass index." We also searched the Cochrane Central Register of Controlled Trials using the above search terms. We conducted the last search on March 14, 2019. A Google search was performed to find any additional studies which may have been omitted in the initial search.

\section{Data Collection and Analysis}

The titles of studies obtained by the above-mentioned search methodology were evaluated systematically. The abstracts were reviewed to determine their suitability for this review, using predefined inclusion criteria. The review of abstracts was done by both authors and any discrepancy was resolved by referring to the predefined inclusion criteria. The full texts of all the studies which were deemed relevant were retrieved and assessed to determine eligibility.

\section{Data Extraction}

A data extraction form was used to extract data from the selected full texts. The data obtained included the year of study publication and name of the first author, number of study participants, type of adrenal insufficiency (primary or secondary), duration of the study, the numbers allocated to the study arms, the study inclusion and exclusion criteria, the characteristics of the study participants, the types and doses of glucocorticoids administered and documented outcomes. The data on infection, adrenal crises and $\mathrm{CV} /$ metabolic outcomes documented were also derived.

\section{Assessment of Quality of Evidence}

The risk of bias in the studies included in this review was systematically evaluated. For RCTs, this included the generation of 
random sequences, the allocation concealment, and the extent of blinding of the study investigators using the Cochrane tool for risk of bias for randomised trials [23].

\section{Results}

The initial search of Medline yielded 6,863 titles. The titles were screened, and 53 abstracts were selected. 49 of these abstracts were eligible for inclusion in this systematic review, and full texts of these 49 studies were evaluated. A further 10 studies were obtained by hand searching of citations from previous reviews and thorough search on Google Scholar, as summarised in Figure 1.

\section{Glucocorticoid Replacement and BMD}

A total of 11 previous studies evaluated the effect of glucocorticoids on BMD although none of these studies were RCTs (cohort studies $n=6$, cross-sectional studies $n=5$ ). Interestingly in 3 of these observational studies carried out by Chandy and Bhatia [18], Leelarathna et al. [24] and Ragnarsson et al. [25], there was a lack of association between glucocorticoid dose and BMD. Similarly, Danilowicz et al. [26] reported no change in BMD measured by bone density scan (dual-energy X-ray absorptiometry) at the hip or lumbar regions with a lower hydrocortisone dose of 10-15 mg. In addition, Chikada et al. [27] observed no association between BMD and hydrocortisone dose for patients who were receiving a lower steroid dose of $13.6 \mathrm{mg} / \mathrm{m}^{2}$. In contrast, Braatvedt et al. [28] and Schulz et al. [16] noted an improved BMD with lower doses of steroid therapy.

The type of steroid regimen influenced bone densityrelated outcomes as reported by Koetz et al. [17], Chandy and Bhatia [18] and Frey et al. [20]. The use of prednisolone was associated with a lower BMD. Frara et al. [19] observed an increased BMD after a switch from hydrocortisone to modified release hydrocortisone.

The studies on glucocorticoid replacement and BMD are shown in Table 1.

\section{Glucocorticoid Replacement and CV/Metabolic \\ Outcomes}

A total of 17 studies were identified which evaluated the effect of glucocorticoids on CV and metabolic outcomes. Thirteen of these studies were observational studies (cohort studies $n=9$, cross-sectional studies $n=4$ ). Three of the 4 randomised trials assessed effects of various types of glucocorticoids on CV and/or metabolic out-

Glucocorticoid Replacement Regimens in

Adrenal Insufficiency comes whereas 1 RCT evaluated the effect of glucocorticoid dose on CV and metabolic outcomes.

The effect of the dose of glucocorticoid replacement on CV and metabolic outcomes was assessed in 6 of the studies. Filipsson et al. [29], Danilowicz et al. [26] and Staufenbiel et al. [30] observed anthropometric benefits of lower doses of glucocorticoid replacement including lower body mass index, body weight and abdominal fat. It was reported that for patients on lower doses of glucocorticoid replacement (20.5 mg hydrocortisone) CV outcomes including lipid profile, glycosylated haemoglobin $\left(\mathrm{HbA}_{1 \mathrm{c}}\right)$, blood pressure and fasting glucose were comparable to controls that were not on glucocorticoid replacement [25]. Reduction in blood pressure (up to $5 \mathrm{~mm} \mathrm{Hg}$ ) was seen with a lower dose of glucocorticoid replacement $[31,32]$.

The CV and metabolic outcomes on different glucocorticoid replacement options were assessed in 11 of the studies. The CV outcomes with modified release hydrocortisone in an RCT by Johannsson et al. [33] included weight reduction of $0.9 \mathrm{~kg}$ with up to $5.5 \mathrm{~mm} \mathrm{Hg}$ blood pressure reduction and a statistically significant decline in $\mathrm{HbA}_{1 c}$. However, there was also a statistically significant increase in serum triglycerides and a decrease in high-density lipoprotein (HDL) cholesterol. Similarly, Giordano et al. [14] observed a significant decrease in waist circumference, $\mathrm{HbA}_{1 \mathrm{c}}$ and low-density lipoprotein (LDL) cholesterol with modified release hydrocortisone. Frara et al. [19] reported reduction in fasting glucose with modified release hydrocortisone treatment over 2 years. Mongiò et al. [34] also reported improved $\mathrm{HbA}_{1 \mathrm{c}}$ and lipid profile in individuals with primary adrenal insufficiency treated with modified release hydrocortisone.

In a randomised trial, Isidori et al. [10] reported a weight reduction benefit of $4 \mathrm{~kg}$ over 24 weeks with modified release hydrocortisone compared to the standard treatment group in addition to a significant reduction in $\mathrm{HbA}_{1 \mathrm{c}}$.

The CV safety of prednisolone was observed in a crosssectional study by Smith et al. [35], who observed no differences in waist circumference, body weight, $\mathrm{HbA}_{1 \mathrm{c}}$, blood pressure, total and LDL cholesterol between hydrocortisone and prednisolone treatment. However, in this study, patients in the prednisolone group were on much lower doses of equivalent glucocorticoid replacement than in the hydrocortisone group. These results are in contrast with the observations made by Quinkler et al. [36], patients in the prednisolone arm had a higher dose, hydrocortisone equivalent $20 \mathrm{mg}$, than in the study by Smith et al. [35]. Quinkler et al. [36] reported a significant 


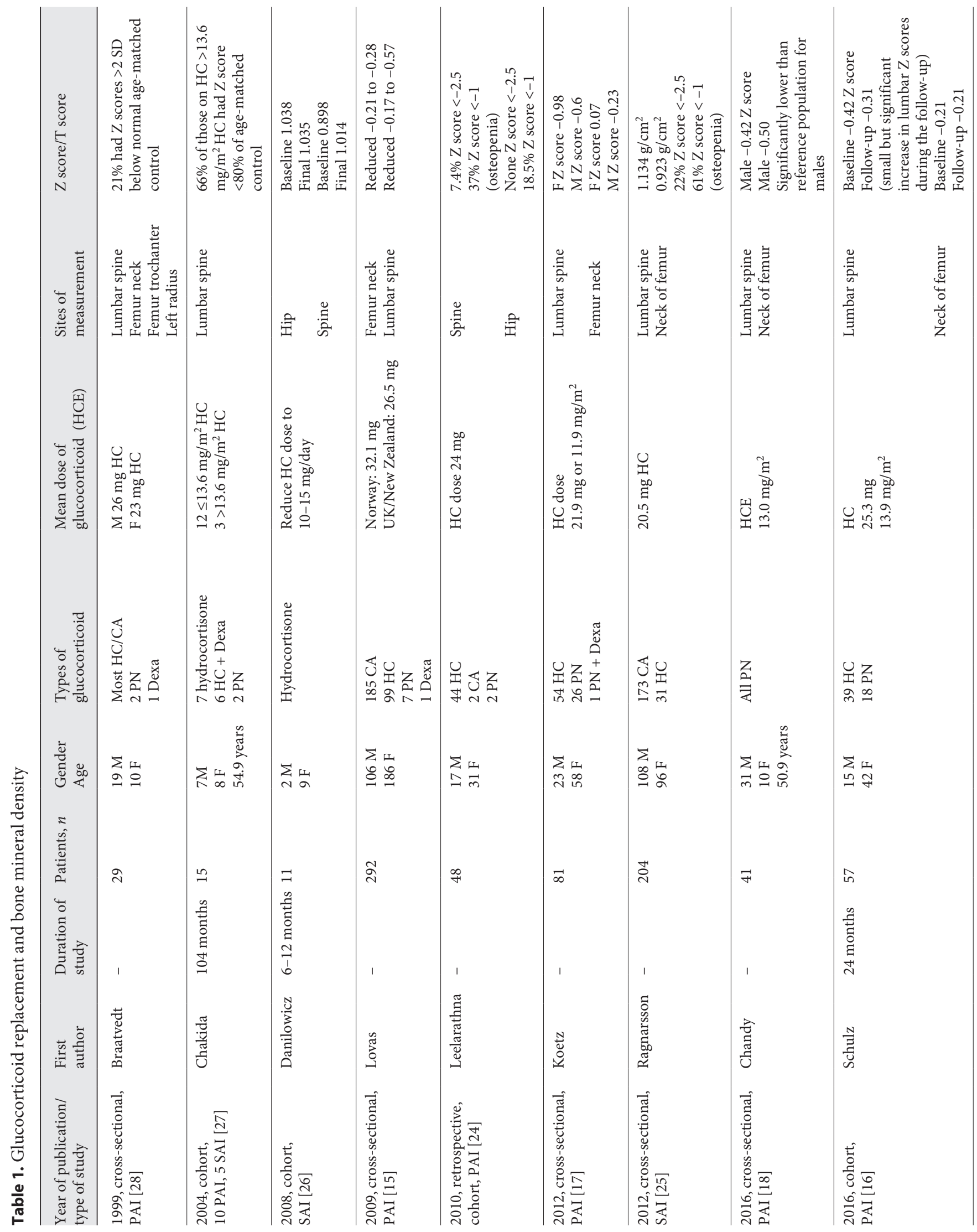




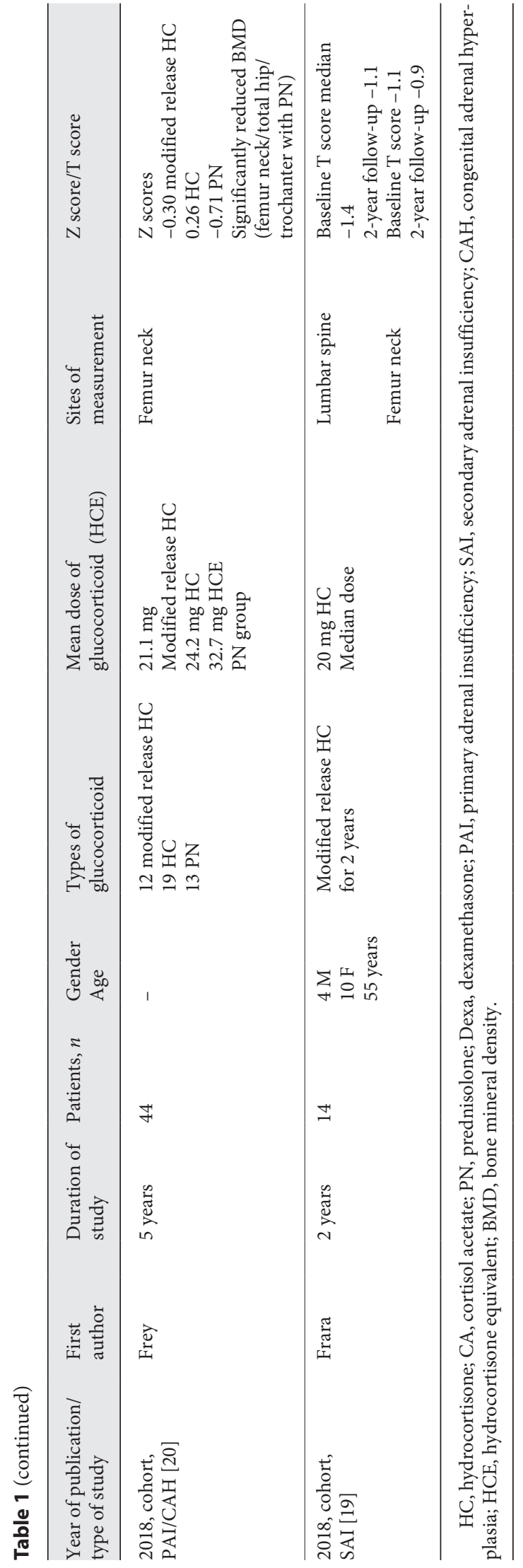

Glucocorticoid Replacement Regimens in Adrenal Insufficiency

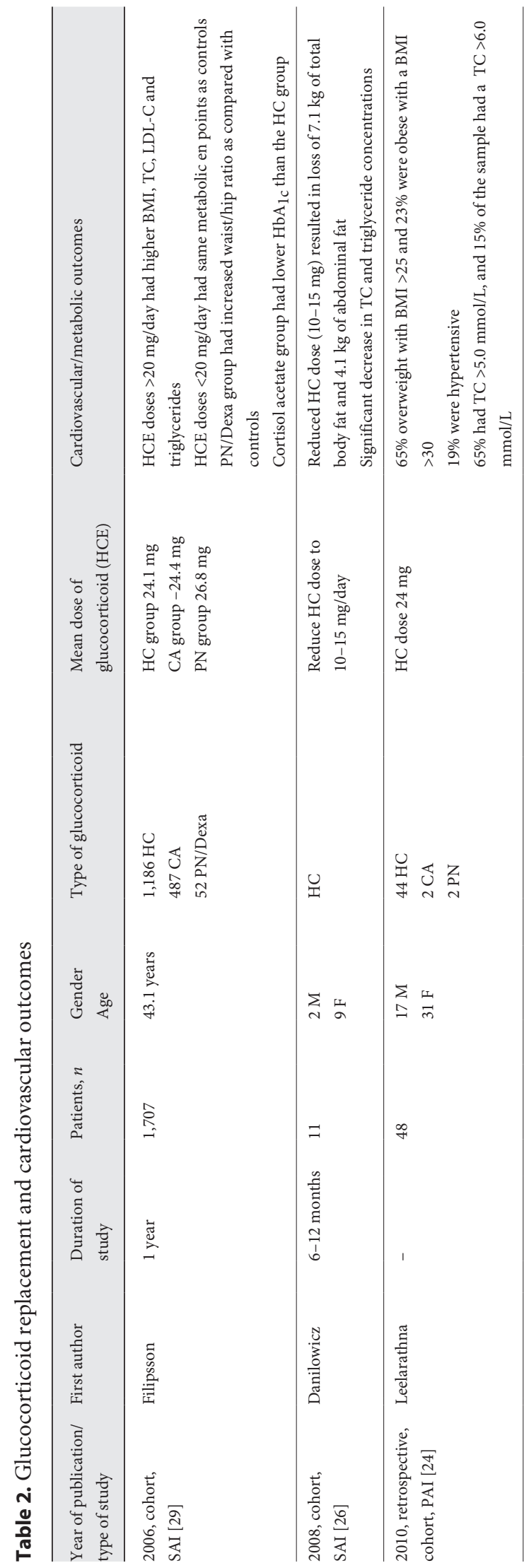

Dubai Diabetes Endocrinol J 2020;26:50-68 


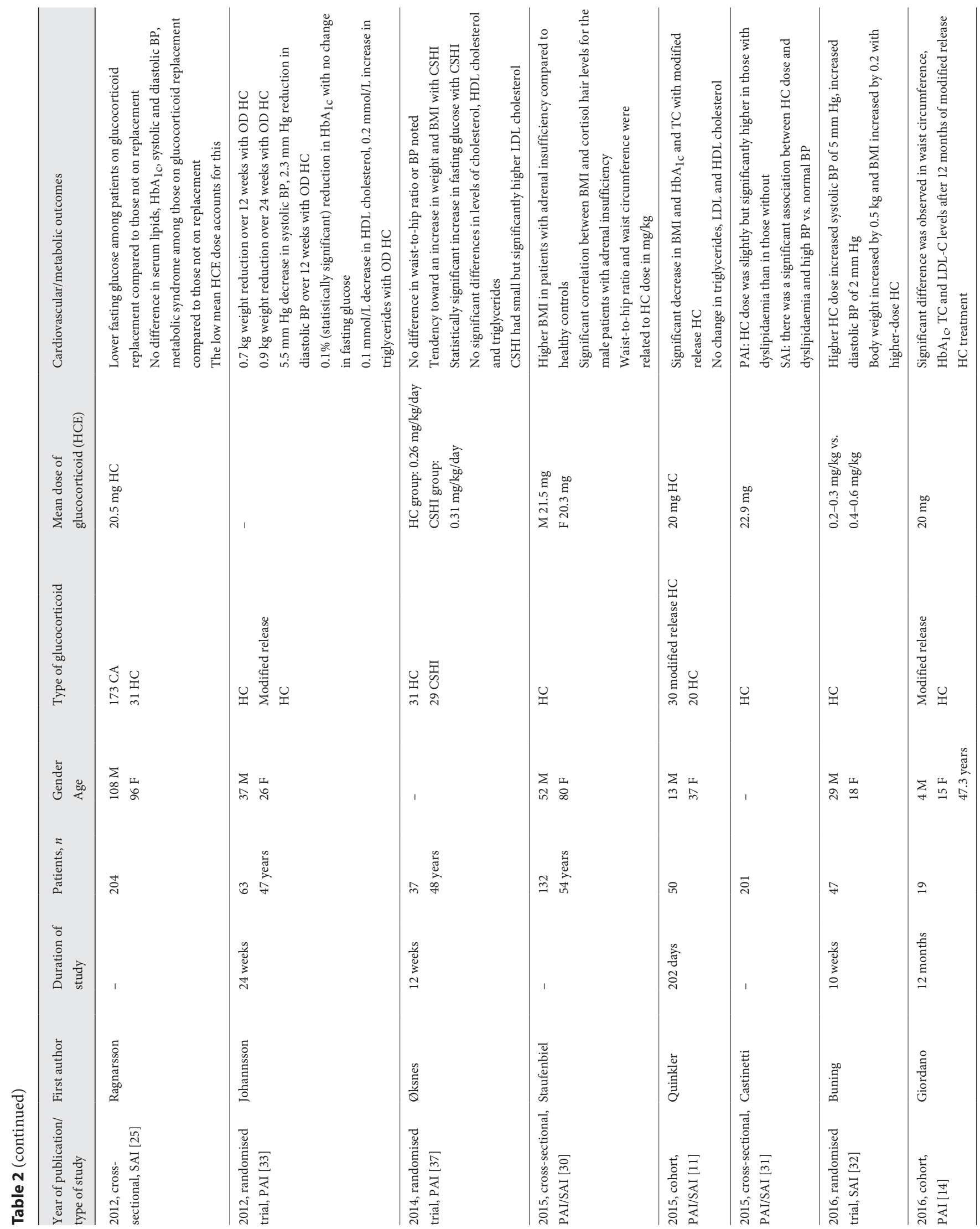




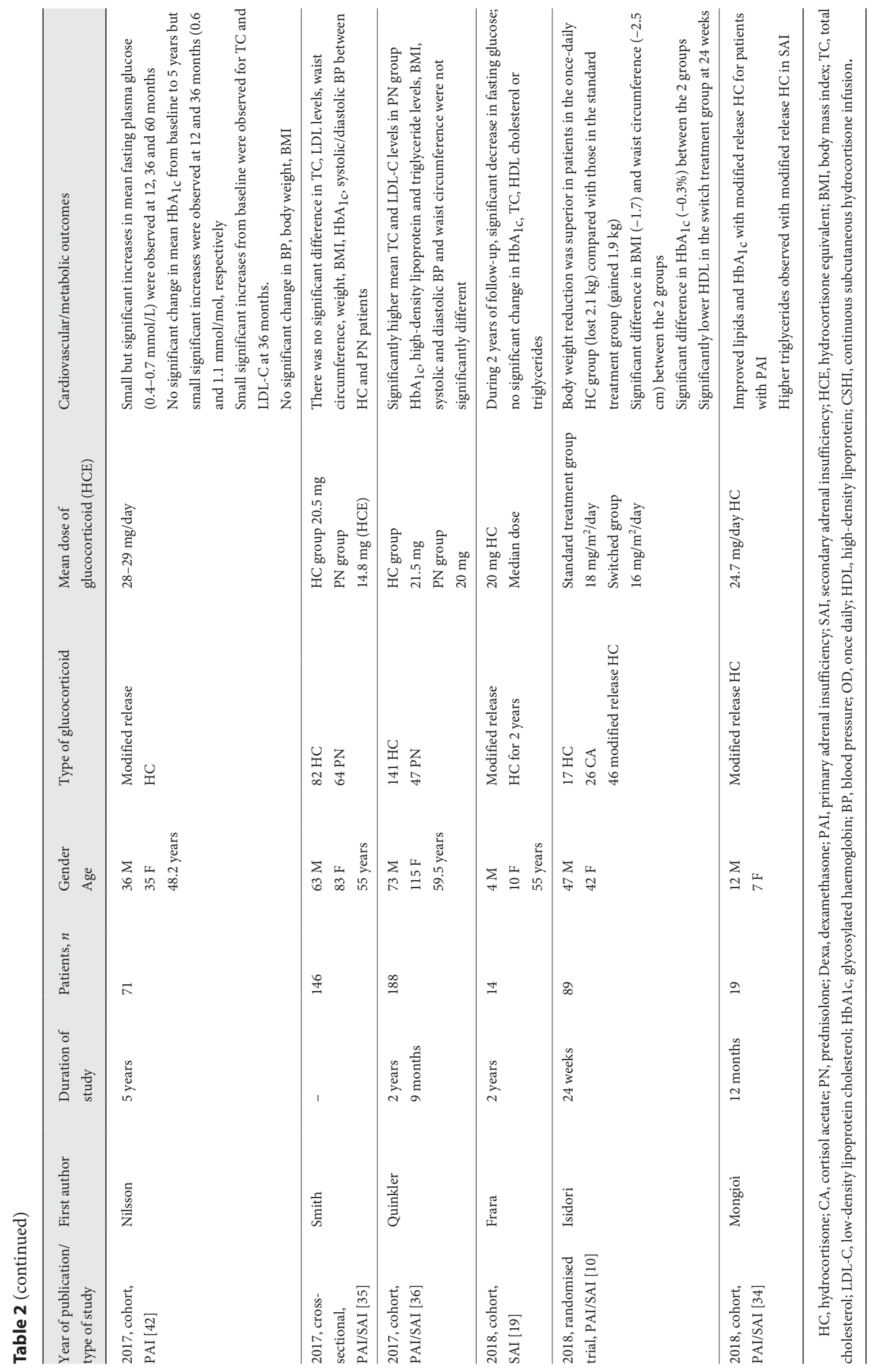




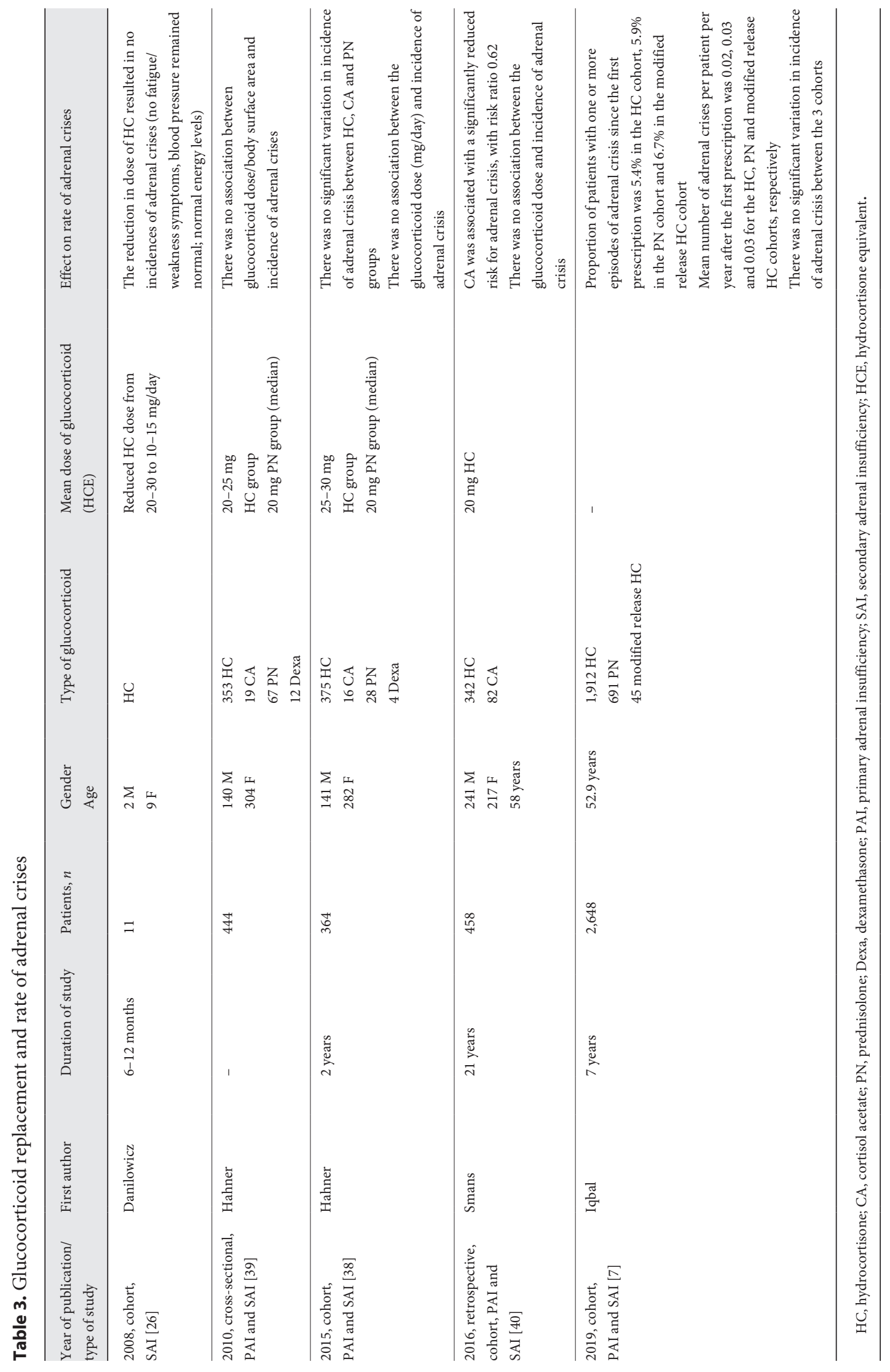




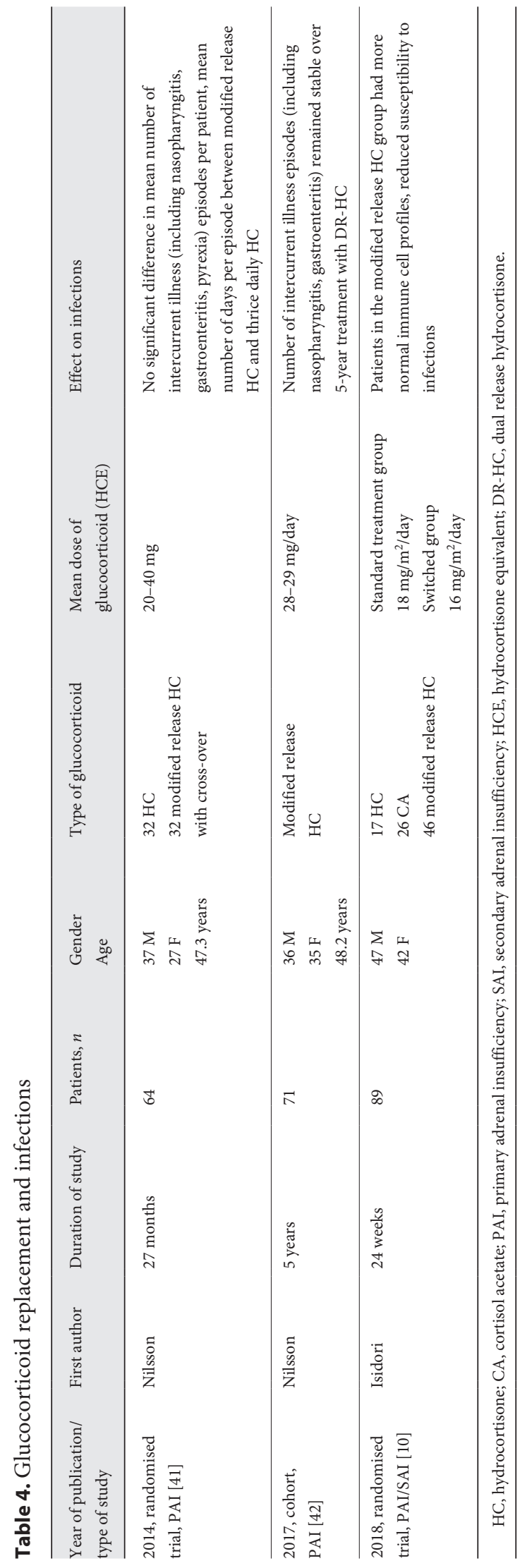

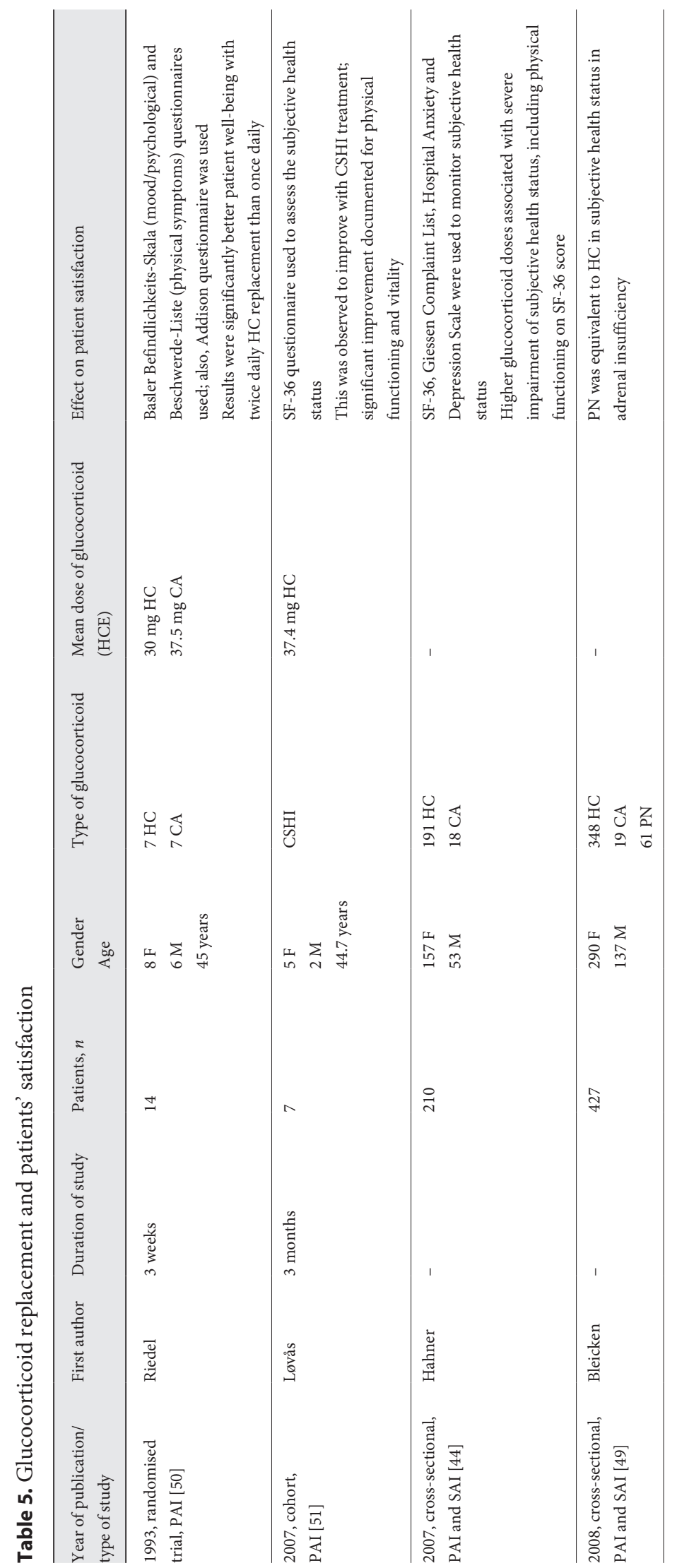




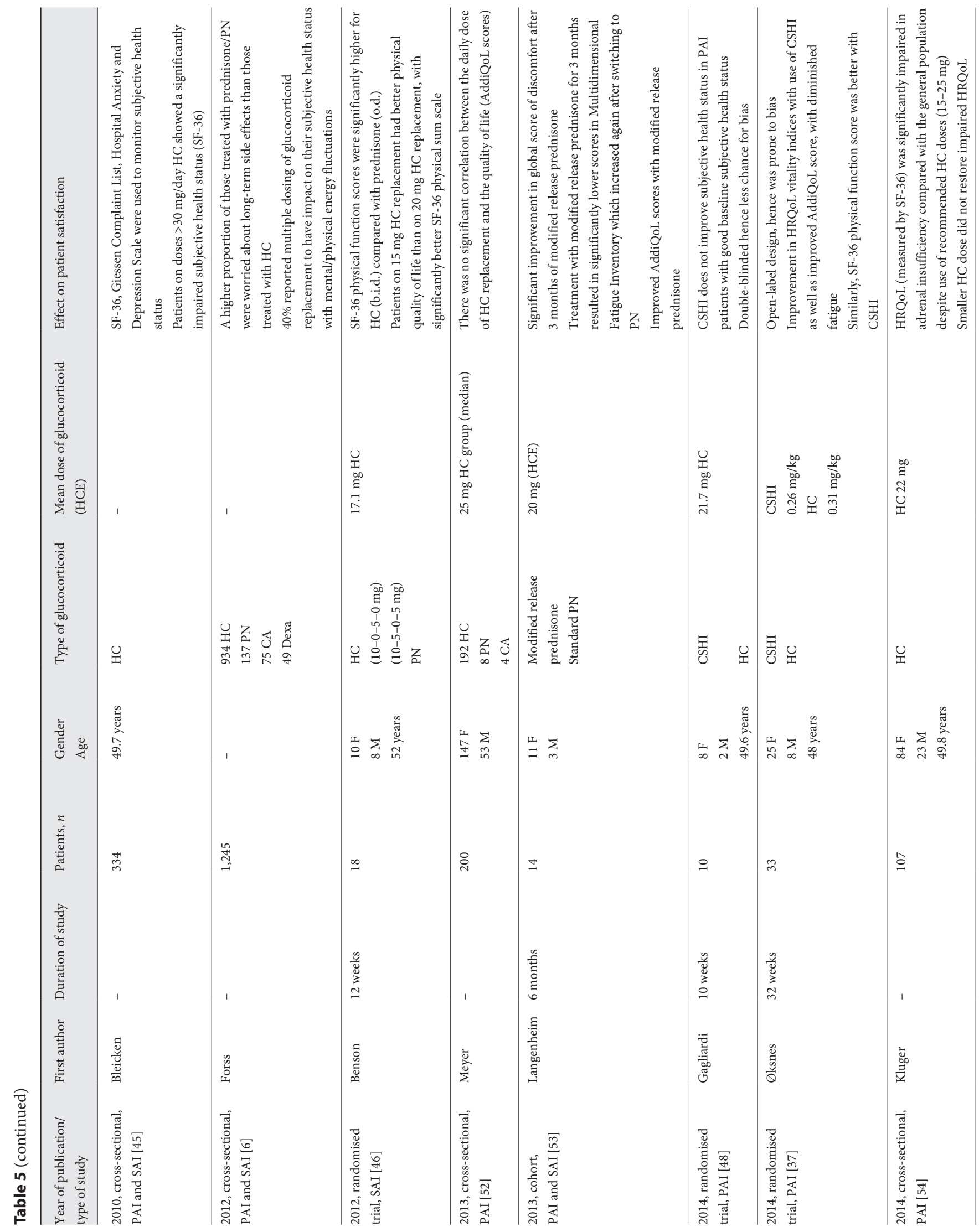




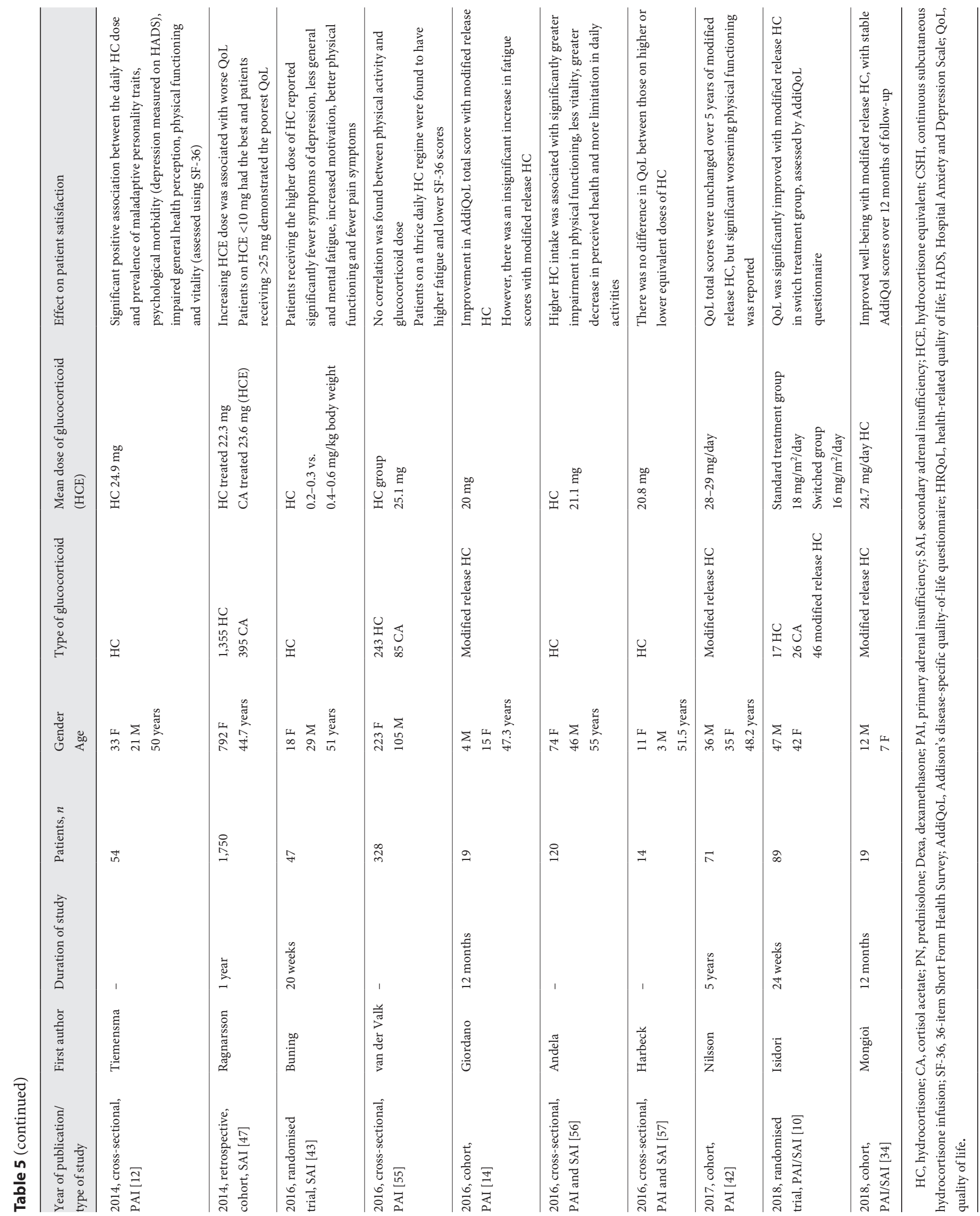


increase in LDL and total cholesterol among patients on prednisolone.

Regarding CV outcomes with cortisol acetate, a study by Filipsson et al. [29] reported lower $\mathrm{HbA}_{1 \mathrm{c}}$ with cortisol acetate treatment compared to hydrocortisone. Additionally, the cardiometabolic consequences of continuous subcutaneous hydrocortisone infusion were assessed by Øksnes et al. [37], who observed an increase in fasting glucose, weight/body mass index compared to patients on conventional hydrocortisone, however with no reported variation in lipid profile (including HDL and LDL cholesterol and triglycerides), insulin or homeostasis model assessment index (other than a trend to an increase in the latter with continuous subcutaneous hydrocortisone infusion). These outcomes are summarised in Table 2.

\section{Glucocorticoid Replacement and Rate of Adrenal}

Crises

We identified 5 observational studies which evaluated the effect of glucocorticoid dose/regimen on the rate of adrenal crises. The effect of the dose of glucocorticoid replacement on the rate of adrenal crises was assessed in 4 out of these 5 studies. None of these studies reported a significant association between the dose of glucocorticoid and the rate of adrenal crisis. Danilowicz et al. [26] reported no difference in the incidence of adrenal crisis with a lower dose of hydrocortisone (10-15 mg). Similarly, Hahner et al. [38, 39] and Smans et al. [40] observed no association between the participants' dose of glucocorticoid and the rate of adrenal crisis.

Three of the studies evaluated the impact of the type of steroid therapy on the development of adrenal crises. Iqbal et al. [7] reported the mean incidence of adrenal crisis per patient of $0.02,0.03$ and 0.03 among patients on hydrocortisone, prednisolone and modified release hydrocortisone, respectively, with no significant difference among the 3 cohorts. Hahner et al. [38] found no association between type of glucocorticoid (hydrocortisone, cortisol acetate or prednisolone) and adrenal crisis.

This contrasts the findings of Smans et al. [40], who observed an association of cortisol acetate with a significantly lower risk of adrenal crisis (risk ratio 0.62). These results are summarised in Table 3.

\section{Glucocorticoid Replacement and Infections}

We identified 3 studies which evaluated the impact of glucocorticoid regimen (modified release hydrocortisone) on the rate of development of infections. In a randomised trial, Nilsson et al. [41] compared patients on modified release hydrocortisone and immediate release hydrocortisone and found a similar number of intercurrent illnesses (such as nasopharyngitis, gastroenteritis, febrile episodes) between the 2 groups. During a 5 -year follow-up on modified release hydrocortisone, the rates of intercurrent illness remained stable [42]. Isidori et al. [10] found reduction in the occurrence of infections in the patients allocated to modified release hydrocortisone, as measured by a total infection score, with a decrease in flu episodes compared to conventional glucocorticoid replacement. These findings are shown in Table 4.

\section{Glucocorticoid Replacement and Patients' Satisfaction}

We identified a total of 22 studies (RCTs $n=7$, observational studies $n=15$ ) which evaluated the effect of glucocorticoids on patients' satisfaction and their quality of life. Ten of the studies assessed the impact of glucocorticoid dose on the patients' satisfaction and quality of life. Only 1 of the studies reported a subjective improvement in symptoms with higher doses of steroid therapy. On the other hand, 5 of the studies reported worsening of the symptoms while 4 of the studies reported no change in patient satisfaction with higher steroid dose.

Buning et al. [43] observed patients on higher doses of hydrocortisone to have better well-being, physical functioning and motivation with reduced pain and fatigue symptoms. This contrasts the findings of Hahner et al. [44], Bleicken et al. [45], Benson et al. [46], Tiemensma et al. [12], Ragnarsson et al. [47], who showed deterioration in subjective health status as well as physical functioning and vitality with higher doses of glucocorticoids.

Ten studies evaluated patients' satisfaction and quality of life on various glucocorticoid replacement regimens. Løvås and Husebye [51] and Øksnes et al. [37] reported improvement in patients' subjective health status, with continuous subcutaneous hydrocortisone infusion. In contrast, Gagliardi et al. [48] found no change in patients' subjective health status with continuous subcutaneous hydrocortisone infusion, provided that the baseline health status was good. Regarding the effect of prednisolone on patients' satisfaction, Bleicken et al. [49] reported a similar patients' report of health status between those on prednisolone and hydrocortisone. Four studies analysed the effect of modified release hydrocortisone on patients' subjective health status. Giordano et al. [14], Mongioì et al. [34] and Isidori et al. [10] reported an improvement in Addison's disease-specific quality-of-life questionnaire scores with modified release hydrocortisone. On the other hand, Nilsson et al. [42] noted some deterioration in physical function over 5 years of use of modified release hydrocortisone. These findings are shown in Table 5.
Kiko/Kalhan 
Fig. 2. Risk of bias assessment. The red shade represents high risk, with green showing low risk and yellow shade representing unclear risk.

\begin{tabular}{|c|c|c|c|c|c|c|}
\hline $\begin{array}{cl}\text { Key : } & \text { High risk } \\
& \text { Unclear risk } \\
& \text { Low risk }\end{array}$ & 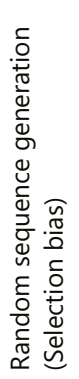 & 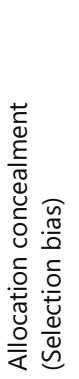 & 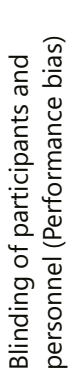 & 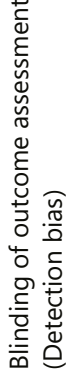 & 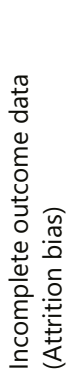 & 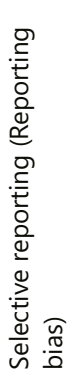 \\
\hline Riedel et al. [50], 1993, Germany & $\square$ & $\square$ & $\square$ & 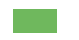 & $\square$ & $\square$ \\
\hline Johannsson et al. [33], 2012, Sweden, USA, UK & $\square$ & Q & Q & Q & $\square$ & $\square$ \\
\hline Benson et al. [46], 2012, Germany & $\square$ & 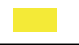 & $\square$ & $\square$ & ב & $\square$ \\
\hline Øksnes et al. [37], 2014, Norway, Sweden & $\square$ & Q & 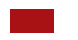 & $\square$ & Q & ב \\
\hline Gagliardi et al. [48], 2014, Australia & $\square$ & $\square$ & $\square$ & $\square$ & $\square$ & $\square$ \\
\hline Nilsson et al. [41], 2014, Sweden & $\square$ & ( & Q & a & $\square$ & 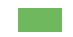 \\
\hline Buning et al. [32], 2016, the Netherlands & $\square$ & $\square$ & $\square$ & $\square$ & $\square$ & $\square$ \\
\hline Buning et al. [43], 2016, the Netherlands & $\square$ & $\square$ & $\square$ & $\square$ & Q & $\square$ \\
\hline Isidori et al. [10], 2018, Italy & 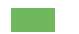 & & & 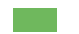 & 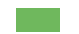 & 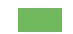 \\
\hline
\end{tabular}

\section{Risk of Bias}

All the 9 randomised trials included in this review had random allocation of participants, which reduced the risk of selection bias. In 5 of these trials, blinding of the study participants was done to reduce the risk of performance bias in these randomised trials. There were incomplete outcome data in 3 of the studies due to attrition. This is shown in Figure 2.

\section{Discussion}

There is a lack of consensus among endocrinologists regarding optimum glucocorticoid dose and regimen with the majority of patients with adrenal insufficiency either receiving hydrocortisone $(15-30 \mathrm{mg} /$ day) or prednisolone (3-7.5 $\mathrm{mg} /$ day) based on regional/local practices. The evaluation of an adequate steroid replacement dose/regimen relies on symptom control, clinical examination (volume status, postural drop of blood pressure, features of underreplacement such as buccal and mucosal pigmentation or overreplacement such as proximal myopathy, easy bruisability and purple stria on abdomen) and biochemical parameters (serum electrolytes, urea, etc.). The cortisol day curve which was used previously for steroid dose titration has been shown to be non-reliable and used infrequently in clinical practice. In addition, the synthetic steroid preparations are unable to rep- licate the synchronised circadian alteration of cortisol levels under physiological states. Considering these limitations, we carried out a systematic review of published evidence related to the impact of various glucocorticoid regimens and doses on BMD, CV and metabolic parameters, incidence of adrenal crisis, infection rate and patient satisfaction.

Our systematic review shows conflicting results on the impact of the dose of glucocorticoid replacement on BMD. A higher steroid dose was shown to lead to reduced BMD in 3 of the studies in contrast to 1 study which showed an improved BMD with a higher dose while 4 of the studies reported no differential impact of glucocorticoid dose on BMD [16-18, 24-28]. The major limitation with all of these 8-studies includes an observational design which is clearly an inferior level of evidence as compared to well-designed RCTs. In addition, the study population was heterogeneous with confounding factors which could have impacted the final results.

Prednisolone use was reported to be associated with a reduced BMD in 3 of the observational studies although the limitations reported include a small sample size of studies, the impact of prior glucocorticoid therapy before commencement of the study and the lack of randomisation $[17,18,20]$. One recent study reported an increase in BMD with modified release hydrocortisone. It was postulated that modified release hydrocortisone reversed the excessive control of bone turnover by supraphysiological 
Table 6. Cardiovascular outcomes from randomised trials on modified release hydrocortisone

\begin{tabular}{|c|c|c|}
\hline Parameter & Johannsson et al. [33] & Isidori et al. [10] \\
\hline Body weight & $\begin{array}{l}\text { Weight reduction } 0.7 \mathrm{~kg} \text { difference compared to standard } \\
\text { glucocorticoid treatment over } 12 \text { weeks }\end{array}$ & $\begin{array}{l}\text { Weight reduction } 4 \mathrm{~kg} \text { difference compared to standard } \\
\text { glucocorticoid treatment in } 24 \text { weeks }\end{array}$ \\
\hline Body mass index & - & Reduction by 1.7 with modified release HC over 24 weeks \\
\hline Waist circumference & - & $\begin{array}{l}\text { Reduction in waist circumference by } 2.5 \mathrm{~cm} \text { with modified } \\
\text { release HC }\end{array}$ \\
\hline $\mathrm{HbA}_{1 \mathrm{c}}$ & $\begin{array}{l}\text { Reduction in } \mathrm{HbA}_{1 \mathrm{c}} \text { by } 0.1 \% \text { with } 0.6 \% \text { reduction in patients } \\
\text { with } \mathrm{DM} \text { at } 12 \text { weeks }\end{array}$ & Reduction in $\mathrm{HbA}_{1 \mathrm{c}}$ by $0.3 \%$ at 24 weeks \\
\hline LDL cholesterol & No significant difference with the treatment & No significant difference with the treatment \\
\hline Triglycerides & Reduction in triglycerides by $0.2 \mathrm{mmol} / \mathrm{L}$ at 12 weeks & No significant change with the treatment \\
\hline HDL cholesterol & Reduction in HDL cholesterol by $0.1 \mathrm{mmol} / \mathrm{L}$ at 12 weeks & Reduction in HDL cholesterol by $0.23 \mathrm{mmol} / \mathrm{L}$ at 24 weeks \\
\hline Systolic blood pressure & Difference of $-5.5 \mathrm{~mm} \mathrm{Hg}$ compared to standard treatment & - \\
\hline Diastolic blood pressure & Difference of $-2.3 \mathrm{~mm} \mathrm{Hg}$ compared to standard treatment & - \\
\hline
\end{tabular}

HC, hydrocortisone; $\mathrm{HbA}_{1 \mathrm{c}}$, glycosylated haemoglobin; DM, diabetes mellitus; LDL, low-density lipoprotein; HDL, high-density lipoprotein.

conventional cortisol replacement. However, this study had a small sample size, and the participants were enrolled retrospectively [19].

Well-recognised CV and metabolic adverse effects of exogenous glucocorticoids include weight gain, hypertension and impaired glucose tolerance [35]. Out of the 6 studies which evaluated the effect of steroid dose on CV risk factors, 5 were observational studies and 1 an RCT. The RCT reported a reduced blood pressure of up to $5 \mathrm{~mm} \mathrm{Hg}$ apart from a decrease in body weight with a lower dose of hydrocortisone $(0.2-0.3 \mathrm{mg} / \mathrm{kg}$ body weight) [32]. The results from the 5 observational studies were also consistent with RCT results. Use of a lower dose of corticosteroids was associated with CV benefit including lower weight, body mass index, abdominal fat, waist circumference, waist-hip ratio, $\mathrm{HbA}_{1 \mathrm{c}}$ and blood pressure $[25,26,29-31]$. The improved CV and metabolic outcomes with a lower dose of glucocorticoids is not surprising considering the historical preference for a relatively higher dose of steroid replacement in patients with adrenal insufficiency. The advances in the measurement of cortisol have shown a daily cortisol production of 5.7-7.4 $\mathrm{mg} / \mathrm{m}^{2} /$ day which equates to $9.5-10.0 \mathrm{mg} /$ day of cortisol for an average individual under physiological conditions [58].

We could identify only 3 RCTs which compared CV and metabolic outcomes with different glucocorticoid replacement options. Two of these RCTs assessed CV out- comes with modified release hydrocortisone while one of the RCTs evaluated the effects of continuous subcutaneous hydrocortisone infusion. A significant reduction in body weight and $\mathrm{HbA}_{1 \mathrm{c}}$ was noted with the use of modified release hydrocortisone; however, there was also a significant decrease in HDL cholesterol in both these trials $[10,33]$. In the study by Isidori et al. [10] there was a significantly higher reduction in body weight with modified release hydrocortisone among patients with secondary adrenal insufficiency. Table 6 sums up the cardiometabolic outcomes observed with the use of modified release hydrocortisone tablets.

The cardiometabolic effects of subcutaneous hydrocortisone infusion were evaluated in an RCT by Øksnes et al. [37], who reported a mild increase in weight and fasting sugars with continuous subcutaneous hydrocortisone infusion with no effect on blood pressure. It was speculated that the findings might have been attributed to a higher hydrocortisone dose resulting in elevated urine cortisol and salivary cortisone in the continuous subcutaneous hydrocortisone infusion group compared to individuals receiving oral hydrocortisone.

The safety of a glucocorticoid replacement regimen has been of paramount importance in patients with adrenal insufficiency especially considering an increased mortality in this cohort [59]. We identified 5 observational studies which evaluated the effect of glucocorticoid on the incidence of adrenal crises. None of these 
Table 7. Impact of type of glucocorticoid on subjective health status

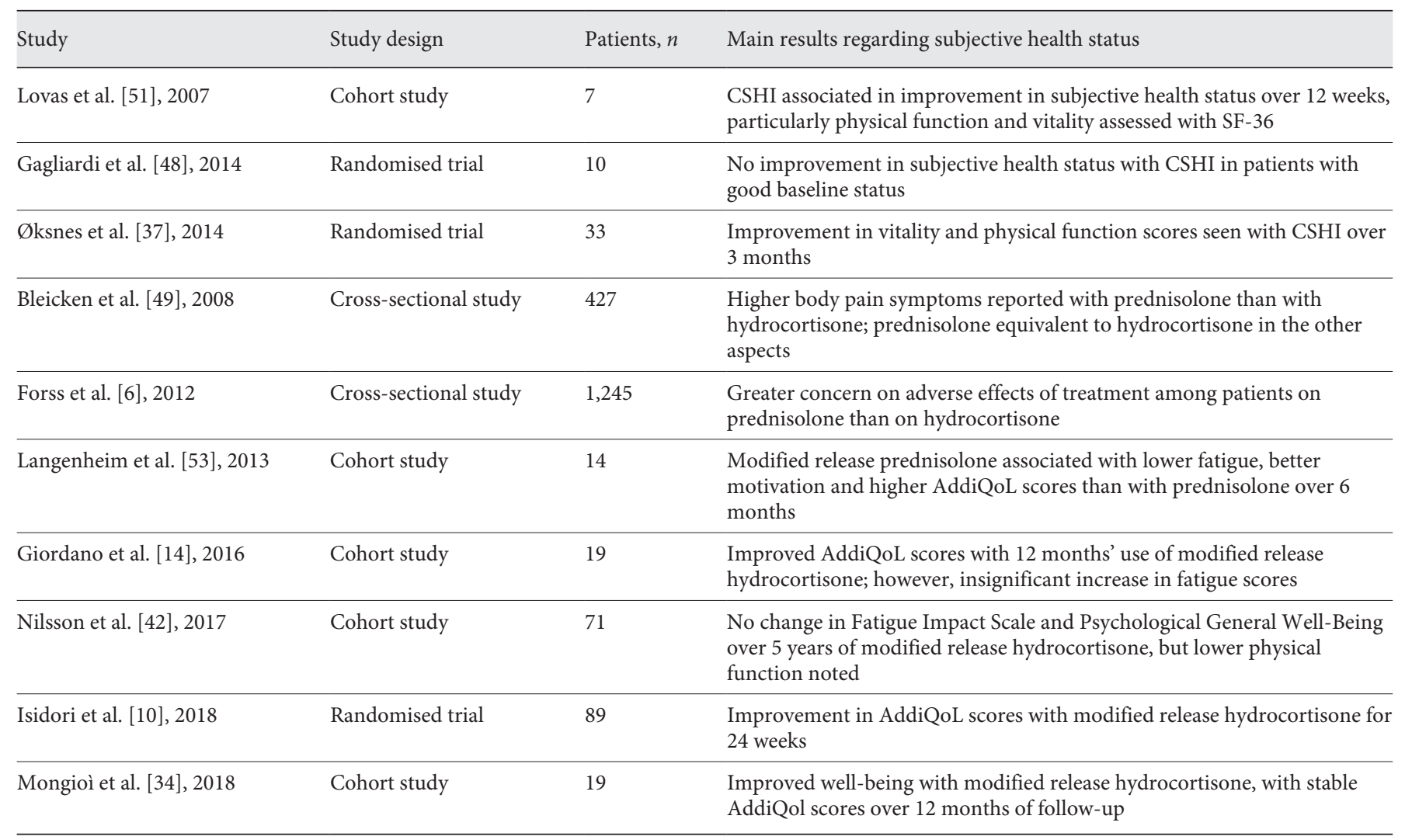

CSHI, continuous subcutaneous hydrocortisone infusion; SF-36, 36-item Short-Form Health Survey; AddiQoL, Addison's disease-specific quality-of-life questionnaire.

studies reported an increase in the risk of development of adrenal crisis with a lower glucocorticoid dose. A lower hydrocortisone dose (10-15 $\mathrm{mg} /$ day) was observed to be equally safe as compared to the historically used higher dose as far as the incidence of adrenal crises [26] was concerned. We also observed no conclusive evidence for the superiority of a particular glucocorticoid regimen in lowering the incidence of adrenal crises (including modified release hydrocortisone, prednisolone and hydrocortisone), except for cortisol acetate which was reported in one observational study to have a significant reduction in risk of adrenal crisis (relative risk 0.62). The study had limitations including a retrospective design, lack of randomisation, low number of adrenal crisis overall and insufficient number of participants on longer-acting glucocorticoids to draw a meaningful inference for this subgroup [40].

The majority of adrenal crises are precipitated by infections (gastroenteritis, respiratory and urinary tract in- fections, and viral infections) $[38,40]$. The infection risk in patients with adrenal insufficiency is increased with over- or underreplacement with glucocorticoid replacement therapy considering the immunosuppressive effects of the treatment per se [10]. We identified 2 RCTs and 1 observational study which evaluated the effects of glucocorticoid replacement (modified release hydrocortisone) on the rate of development of infection. The largest of these studies $(n=89)$ reported a normal immune profile with reduced infection scores with modified release hydrocortisone tablets [10].

In hypoadrenalism, the impairment in patients' subjective health status is attributable, at least in part, to the intrinsic shortcomings of glucocorticoid replacement therapy [12]. In a systematic review and meta-analysis, $\mathrm{Al}$ Nofal et al. [21] reported improved quality of life with modified release hydrocortisone and continuous subcutaneous hydrocortisone infusion compared to immediate release hydrocortisone. 
We included 6 RCTs which assessed the effect of the type or dose of glucocorticoid replacement on quality of life of the patients with adrenal insufficiency. The results of these 6 RCTs presented conflicting observations pertaining to the impact of glucocorticoid dose on subjective quality of life and patients' satisfaction. Buning et al. [43] reported benefits of a higher dose to include lower fatigue, higher motivation and better physical function. This contrasts with the findings of Benson et al. [46], who reported improved physical function with a lower dose of hydrocortisone. The effect of various glucocorticoid treatment options on patients' subjective health status as seen in the randomised trials was also conflicting, particularly for continuous subcutaneous hydrocortisone infusion, with no increase in patient satisfaction with continuous subcutaneous hydrocortisone infusion reported by Gagliardi et al. [48] whereas Øksnes et al. [37] found improved physical function and reduced fatigue with this treatment. The reasons behind this difference were postulated to be due to the good baseline subjective health status among patients studied by Gagliardi et al. [48]; in addition, the trial carried out by Øksnes et al. [37] was not blinded hence was prone to bias. In a randomised trial by Isodari et al. [10], improvement in patients' quality of life by up to 9 points of Addison's disease-specific quality-of-life questionnaire scores was reported. One of the flaws which could be identified for these studies includes that the study participants were not masked (single-blinded study) which predisposes the participants to recollection bias. These results are shown in Table 7.

Our systematic review has several strengths and limitations. We carried out a comprehensive search using multiple databases and included a wide source of publications. We included 47 studies to carry out systematic review and followed the PRISMA statement. A predefined proforma helped analyse and compare the studies while an independent observer screened the studies for potential commercial bias. The major limitations of this systematic search remains a dearth in high-quality RCTs which could have compared the various glucocorticoid regimens prospectively. The majority of the studies which have been carried out in this field are observational with the majority of these being uncontrolled and/or having a cross-sectional design with a relatively short follow-up duration. This itself leads to an inferior quality of evidence This was a significant constraint related to the evidence which was available from the literature search. Also, we did not evaluate the impact of fludrocortisone and androgen replacement such as dehydroepiandrosterone sulphate on the subjective health status of patients with adrenal insufficiency.
One of the key observations of our systematic review (based on the evidence from a single RCT and multiple observational studies) suggests a lower dose of glucocorticoid replacement associated with improved CV outcomes apart from lower blood pressure, body weight, $\mathrm{HbA}_{1 \mathrm{c}}$ and waist circumference [25, 30-32]. In addition, evidence from relatively short duration trials suggests that modified release hydrocortisone is efficacious in lowering CV risk [10, 33]. However, there is a need for longer-duration studies to assess further whether these cardiometabolic benefits could be sustained over a period of time. From a single randomised trial, continuous subcutaneous hydrocortisone infusion provided no benefit in the reduction of CV risk factors [37].

Based on our systematic review, we observed no difference in the risk of adrenal crises based on regimen and dose of glucocorticoid used. Furthermore, a reduction in BMD (from 1 cross-sectional study and 2 cohort studies) and elevation of total lipoprotein and LDL was noticed with the use of higher doses of prednisolone $[16,28,36]$. Prednisolone has an established role in the management of adrenal insufficiency with the ongoing debate regarding its efficacy as compared to hydrocortisone in patients with primary as well as secondary adrenal insufficiency. Based on our systematic review, prednisolone use can be deemed safe and efficacious in patients with adrenal insufficiency. In addition, prednisolone therapy offers a more economical alternative to hydrocortisone which offers long-term health-economic benefits; however, where generic medications are available, the price difference may not be significant.

Most of the evidence in the current systematic review was obtained from short-term follow-up randomised trials and observational studies. There is a need for longterm follow-up double-blinded randomised trials to assess the effects of the type of glucocorticoid on subjective quality of life, CV factors, BMD, adrenal crises and infections in patients with adrenal insufficiency.

\section{Acknowledgement}

This research did not receive any support from any other individuals or organisations.

\section{Disclosure Statement}

There is no conflict of interest that could be perceived as prejudicing the impartiality of the research reported.
Kiko/Kalhan 


\section{Funding Sources}

This research did not receive any specific grant from any funding agency in the public, commercial or not-for-profit sector.

\section{Author Contributions}

Both authors were involved in conducting the systematic review and preparation of this paper.

\section{References}

1 Bornstein SR, Allolio B, Arlt W, Barthel A, Don-Wauchope A, Hammer GD, et al. Diagnosis and treatment of primary adrenal insufficiency: an endocrine society clinical practice guideline. J Clin Endocrinol Metab. 2016 Feb; 101(2):364-89.

2 Ueland GA, Husebye ES. Metabolic Complications in Adrenal Insufficiency. Front Horm Res. 2018;49:104-13.

3 Husebye ES, Allolio B, Arlt W, Badenhoop K, Bensing S, Betterle C, et al. Consensus statement on the diagnosis, treatment and followup of patients with primary adrenal insufficiency. J Intern Med. 2014 Feb;275(2):10415.

4 Flück CE. MECHANISMS IN ENDOCRINOLOGY: Update on pathogenesis of primary adrenal insufficiency: beyond steroid enzyme deficiency and autoimmune adrenal destruction. Eur J Endocrinol. 2017 Sep; 177(3):R99-111.

5 Bancos I, Hahner S, Tomlinson J, Arlt W. Diagnosis and management of adrenal insufficiency. Lancet Diabetes Endocrinol. 2015 Mar;3(3):216-26.

6 Forss M, Batcheller G, Skrtic S, Johannsson G. Current practice of glucocorticoid replacement therapy and patient-perceived health outcomes in adrenal insufficiency - a worldwide patient survey. BMC Endocr Disord. 2012 Jun;12(1):8.

7 Iqbal K, Halsby K, Murray RD, Carroll PV, Petermann R. Glucocorticoid management of adrenal insufficiency in the United Kingdom: assessment using real-world data. Endocr Connect. 2019 Jan;8(1):20-31.

8 Dallman MF, Akana SF, Bhatnagar S, Bell ME, Strack AM. Bottomed out: metabolic significance of the circadian trough in glucocorticoid concentrations. Int J Obes Relat Metab Disord. 2000 Jun;24(Suppl 2):S40-6.

9 Björnsdottir S, Øksnes M, Isaksson M, Methlie P, Nilsen RM, Hustad S, et al. Circadian hormone profiles and insulin sensitivity in patients with Addison's disease: a comparison of continuous subcutaneous hydrocortisone infusion with conventional glucocorticoid replacement therapy. Clin Endocrinol (Oxf). 2015 Jul;83(1):28-35.

10 Isidori AM, Venneri MA, Graziadio C, Simeoli C, Fiore D, Hasenmajer V, et al. Effect of once-daily, modified-release hydrocortisone versus standard glucocorticoid therapy on metabolism and innate immunity in patients with adrenal insufficiency (DREAM): a single-blind, randomised controlled trial. Lancet Diabetes Endocrinol. 2018 Mar;6(3):173-85.
11 Quinkler M, Miodini Nilsen R, Zopf K, Ventz M, Øksnes M. Modified-release hydrocortisone decreases BMI and HbAlc in patients with primary and secondary adrenal insufficiency. Eur J Endocrinol. 2015 May;172(5): 619-26.

12 Tiemensma J, Andela CD, Kaptein AA, Romijn JA, van der Mast RC, Biermasz NR, et al. Psychological morbidity and impaired quality of life in patients with stable treatment for primary adrenal insufficiency: cross-sectional study and review of the literature. Eur J Endocrinol. 2014 Aug;171(2):171-82.

13 Heald AH, Walther A, Davis JR, Moreno GY, Kane J, Livingston $\mathrm{M}$, et al. No difference in mood and quality of life in dhea-s deficient adults with addison's disease vs. type 2 diabetes patients with normal DHEA-S levels: implications for management of these conditions. Front Psychol. 2017 May;8:764.

14 Giordano R, Guaraldi F, Marinazzo E, Fumarola F, Rampino A, Berardelli R, et al. Improvement of anthropometric and metabolic parameters, and quality of life following treatment with dual-release hydrocortisone in patients with Addison's disease. Endocrine. 2016 Feb;51(2):360-8.

15 Løvås K, Gjesdal CG, Christensen M, Wolff $\mathrm{AB}$, Almås B, Svartberg J, et al. Glucocorticoid replacement therapy and pharmacogenetics in Addison's disease: effects on bone. Eur J Endocrinol. 2009 Jun;160(6):993-1002.

16 Schulz J, Frey KR, Cooper MS, Zopf K, Ventz $\mathrm{M}$, Diederich S, et al. Reduction in daily hydrocortisone dose improves bone health in primary adrenal insufficiency. Eur J Endocrinol. 2016 Apr;174(4):531-8.

17 Koetz KR, Ventz M, Diederich S, Quinkler M. Bone mineral density is not significantly reduced in adult patients on low-dose glucocorticoid replacement therapy. J Clin Endocrinol Metab. 2012 Jan;97(1):85-92.

18 Chandy DD, Bhatia E. Bone mineral density in patients with Addison disease on replacement therapy with prednisolone. Endocr Pract. 2016 Apr;22(4):434-9.

19 Frara S, Chiloiro S, Porcelli T, Giampietro A, Mazziotti G, De Marinis L, et al. Bone safety of dual-release hydrocortisone in patients with hypopituitarism. Endocrine. 2018 Jun; 60(3):528-31.

20 Frey KR, Kienitz T, Schulz J, Ventz M, Zopf $\mathrm{K}$, Quinkler M. Prednisolone is associated with a worse bone mineral density in primary adrenal insufficiency. Endocr Connect. 2018 Jun;7(6):811-8.
21 Al Nofal A, Bancos I, Benkhadra K, Ospina NM, Javed A, Kapoor E, et al. Glucocorticoid replacement regimens in chronic adrenal insufficiency: a systematic review and metaanalysis. Endocr Pract. 2017 Jan;23(1):17-31.

22 Moher D, Liberati A, Tetzlaff J, Altman DG; PRISMA Group. Preferred reporting items for systematic reviews and meta-analyses: the PRISMA statement. PLoS Med. 2009 Jul; 6(7):e1000097.

23 Higgins JP, Altman DG, Gøtzsche PC, Jüni P, Moher D, Oxman AD, et al.; Cochrane Bias Methods Group; Cochrane Statistical Methods Group. The Cochrane Collaboration's tool for assessing risk of bias in randomised trials. BMJ. 2011 Oct;343:d5928.

24 Leelarathna L, Breen L, Powrie JK, Thomas SM, Guzder R, McGowan B, et al. Co-morbidities, management and clinical outcome of auto-immune Addison's disease. Endocrine. 2010 Aug;38(1):113-7.

25 Ragnarsson O, Nyström HF, Johannsson G. Glucocorticoid replacement therapy is independently associated with reduced bone mineral density in women with hypopituitarism. Clin Endocrinol (Oxf). 2012 Feb;76(2):246-52.

26 Danilowicz K, Bruno OD, Manavela M, Gomez RM, Barkan A. Correction of cortisol overreplacement ameliorates morbidities in patients with hypopituitarism: a pilot study. Pituitary. 2008;11(3):279-85.

27 Chikada N, Imaki T, Hotta M, Sato K, Takano $\mathrm{K}$. An assessment of bone mineral density in patients with Addison's disease and isolated ACTH deficiency treated with glucocorticoid. Endocr J. 2004 Jun;51(3):355-60.

28 Braatvedt GD, Joyce M, Evans M, Clearwater J, Reid IR. Bone mineral density in patients with treated Addison's disease. Osteoporos Int. 1999;10(6):435-40.

29 Filipsson H, Monson JP, KoltowskaHäggström M, Mattsson A, Johannsson G. The impact of glucocorticoid replacement regimens on metabolic outcome and comorbidity in hypopituitary patients. J Clin Endocrinol Metab. 2006 Oct;91(10):3954-61.

30 Staufenbiel SM, Andela CD, Manenschijn L, Pereira AM, van Rossum EF, Biermasz NR. Increased hair cortisol concentrations and $\mathrm{BMI}$ in patients with pituitary-adrenal disease on hydrocortisone replacement. J Clin Endocrinol Metab. 2015 Jun;100(6):2456-62.

31 Castinetti F, Sahnoun M, Albarel F, Morange I, Philippon M, Conte-Devolx B, et al. An observational study on adrenal insufficiency in a French tertiary centre: real life versus theory. Ann Endocrinol (Paris). 2015 Feb;76(1):1-8. 
32 Buning JW, van Faassen M, Brummelman P, Dullaart RP, van den Berg G, van der Klauw MM, et al. Effects of Hydrocortisone on the Regulation of Blood Pressure: Results From a Randomized Controlled Trial. J Clin Endocrinol Metab. 2016 Oct;101(10):3691-99.

33 Johannsson G, Nilsson AG, Bergthorsdottir R, Burman P, Dahlqvist P, Ekman B, et al. Improved cortisol exposure-time profile and outcome in patients with adrenal insufficiency: a prospective randomized trial of a novel hydrocortisone dual-release formulation. I Clin Endocrinol Metab. 2012 Feb;97(2):47381.

34 Mongioì LM, Condorelli RA, La Vignera S, Calogero AE. Dual-release hydrocortisone treatment: glycometabolic profile and healthrelated quality of life. Endocr Connect. 2018 Jan;7(1):211-9.

35 Smith DJ, Prabhudev H, Choudhury S, Meeran K. Prednisolone has the same cardiovascular risk profile as hydrocortisone in glucocorticoid replacement. Endocr Connect. 2017 Nov;6(8):766-72.

36 Quinkler M, Ekman B, Marelli C, Uddin S, Zelissen P, Murray RD; EU-AIR Investigators. Prednisolone is associated with a worse lipid profile than hydrocortisone in patients with adrenal insufficiency. Endocr Connect. 2017 Jan;6(1):1-8.

37 Øksnes M, Björnsdottir S, Isaksson M, Methlie P, Carlsen S, Nilsen RM, et al. Continuous subcutaneous hydrocortisone infusion versus oral hydrocortisone replacement for treatment of addison's disease: a randomized clinical trial. J Clin Endocrinol Metab. 2014 May; 99(5):1665-74.

38 Hahner S, Spinnler C, Fassnacht M, BurgerStritt S, Lang K, Milovanovic D, et al. High incidence of adrenal crisis in educated patients with chronic adrenal insufficiency: a prospective study. J Clin Endocrinol Metab. 2015 Feb;100(2):407-16.

39 Hahner S, Loeffler M, Bleicken B, Drechsler C, Milovanovic D, Fassnacht M, et al. Epidemiology of adrenal crisis in chronic adrenal insufficiency: the need for new prevention strategies. Eur J Endocrinol. 2010 Mar;162(3): 597-602.

40 Smans LC, Van der Valk ES, Hermus AR, Zelissen PM. Incidence of adrenal crisis in patients with adrenal insufficiency. Clin Endocrinol (Oxf). 2016 Jan;84(1):17-22.
41 Nilsson AG, Marelli C, Fitts D, Bergthorsdottir R, Burman P, Dahlqvist P, et al. Prospective evaluation of long-term safety of dual-release hydrocortisone replacement administered once daily in patients with adrenal insufficiency. Eur J Endocrinol. 2014 Sep;171(3): 369-77.

42 Nilsson AG, Bergthorsdottir R, Burman P, Dahlqvist P, Ekman B, Engström BE, et al. Long-term safety of once-daily, dual-release hydrocortisone in patients with adrenal insufficiency: a phase $3 \mathrm{~b}$, open-label, extension study. Eur J Endocrinol. 2017 Jun;176(6): $715-25$.

43 Buning WJ, Brummelman P, Koerts J, Dullaart RP, van den Berg G, van der Klauw MM, et al. Hydrocortisone dose influences pain, depressive symptoms and perceived health in adrenal insufficiency: a randomized controlled trial. Neuroendocrinology. 2016; 103(6):771-8

44 Hahner S, Loeffler M, Fassnacht M, Weismann D, Koschker AC, Quinkler M, et al. Impaired subjective health status in 256 patients with adrenal insufficiency on standard therapy based on cross-sectional analysis. J Clin Endocrinol Metab. 2007 Oct;92(10):3912-22.

45 Bleicken B, Hahner S, Ventz M, Quinkler M. Delayed diagnosis of adrenal insufficiency is common: a cross-sectional study in $216 \mathrm{pa}-$ tients. Am J Med Sci. 2010 Jun;339(6):525-31.

46 Benson S, Neumann P, Unger N, Schedlowski M, Mann K, Elsenbruch S, et al. Effects of standard glucocorticoid replacement therapies on subjective well-being: a randomized, double-blind, crossover study in patients with secondary adrenal insufficiency. Eur J Endocrinol. 2012 Nov;167(5):679-85.

47 Ragnarsson O, Mattsson AF, Monson JP, Filipsson Nyström H, Åkerblad AC, KołtowskaHäggström $M$, et al. The relationship between glucocorticoid replacement and quality of life in 2737 hypopituitary patients. Eur J Endocrinol. 2014 Nov; 171(5):571-9.

48 Gagliardi L, Nenke MA, Thynne TR, von der Borch J, Rankin WA, Henley DE, et al. Continuous subcutaneous hydrocortisone infusion therapy in Addison's disease: a randomized, placebo-controlled clinical trial. J Clin Endocrinol Metab. 2014 Nov;99(11):414957.

49 Bleicken B, Hahner S, Loeffler M, Ventz M, Allolio B, Quinkler M. Impaired subjective health status in chronic adrenal insufficiency: impact of different glucocorticoid replacement regimens. Eur J Endocrinol. 2008 Dec; 159(6):811-7.
50 Riedel M, Wiese A, Schürmeyer TH, Brabant G. Quality of life in patients with Addison's disease: effects of different cortisol replacement modes. Exp Clin Endocrinol. 1993; 101(2):106-11.

51 Løvås K, Husebye ES. Continuous subcutaneous hydrocortisone infusion in Addison's disease. Eur J Endocrinol. 2007 Jul;157(1):109_ 12.

52 Meyer G, Hackemann A, Penna-Martinez M, Badenhoop K. What affects the quality of life in autoimmune Addison's disease? Horm Metab Res. 2013 Feb;45(2):92-5.

53 Langenheim J, Ventz M, Hinz A, Quinkler M. Modified-release prednisone decreases complaints and fatigue compared to standard prednisolone in patients with adrenal insufficiency. Horm Metab Res. 2013 Feb;45(2): 96-101.

54 Kluger N, Matikainen N, Sintonen H, Ranki A, Roine RP, Schalin-Jäntti C. Impaired health-related quality of life in Addison's disease-impact of replacement therapy, comorbidities and socio-economic factors. Clin Endocrinol (Oxf). 2014 Oct;81(4):511-8.

55 van der Valk ES, Smans LC, Hofstetter $\mathrm{H}$ Stubbe JH, de Vries M, Backx FJ, et al. Decreased physical activity, reduced QoL and presence of debilitating fatigue in patients with Addison's disease. Clin Endocrinol (Oxf). 2016 Sep;85(3):354-60.

56 Andela CD, Staufenbiel SM, Joustra SD, Pereira AM, van Rossum EF, Biermasz NR. Quality of life in patients with adrenal insufficiency correlates stronger with hydrocortisone dosage, than with long-term systemic cortisol levels. Psychoneuroendocrinology. 2016 Oct;72:80-6.

57 Harbeck B, Danneberg S, Rahvar AH, Haas CS, Lehnert H, Kropp P, et al. Exploring the impact of short- and long-term hydrocortisone replacement on cognitive function, quality of life and catecholamine secretion: a pilot study. Appl Psychophysiol Biofeedback. 2016 Sep;41(3):341-7.

58 Kerrigan JR, Veldhuis JD, Leyo SA, Iranmanesh A, Rogol AD. Estimation of daily cortisol production and clearance rates in normal pubertal males by deconvolution analysis. J Clin Endocrinol Metab. 1993 Jun;76(6):150510.

59 Bergthorsdottir R, Leonsson-Zachrisson M, Odén A, Johannsson G. Premature mortality in patients with Addison's disease: a population-based study. J Clin Endocrinol Metab. 2006 Dec;91(12):4849-53. 